\title{
Lectin binding patterns and immunohistochemical antigen detection in placenta and lungs of Brucella abortus-bovine infected fetuses
}

\author{
María Andrea Fiorentino ${ }^{1, *}$, Fernando Alberto Paolicchi ${ }^{1}$, Carlos Manuel Campero ${ }^{1}$ and Claudio G. Barbeito ${ }^{2}$ \\ ${ }^{1}$ INTA, Centro Regional Buenos Aires Sur, Estación Experimental Agropecuaria Balcarce, 7620 Balcarce, \\ Argentina \\ ${ }^{2}$ Cátedra de Histología y Embriología e Instituto de Patología, Facultad de Ciencias Veterinarias Universidad \\ Nacional de La Plata, La Plata, B1900 AVW, Argentina
}

\begin{abstract}
Lectin binding relies on the affinity of these substances for specific terminal sugars. The method facilitates the identification of complex structures to which the terminal sugar attaches and may reveal physiological or pathological changes in cells, intracellular interactions or extracellular transport pathways. This study was carried out to investigate the effect of infection with Brucella abortus on the pattern of lectin binding in bovine fetal lungs $(\mathrm{n}=6)$ and bovine placentas $(\mathrm{n}=5)$. Fetal lungs and placenta from heifers experimentally inoculated with $B$. abortus, strain 2308 were examined by histological, lectin-histochemical, immunohistochemical and cultural techniques. B. abortus antigens were immunohistochemically detected in fetal lungs and placenta. An increase in the labeling with UEA-1, DBA, PNA, RCA-1 and SBA was found in the lungs and an increase in the labeling with UEA-1, ConA, PNA, DBA was found in the placentas. The present lectin histochemical study revealed a distinctive pattern of oligosaccharide distribution in the lungs and placenta of $B$. abortus-infected fetuses.
\end{abstract}

Keywords: Bovine fetuses, Brucella abortus, Immunohistochemical, Lectin, Placenta.

\section{Introduction}

Brucella abortus is a Gram negative, facultative intracellular pathogen and the main causative agent of brucellosis in cattle. The disease in pregnant females can result in massive infection of the placenta, which in turn, leads to infertility and abortion in the late stages of gestation (Olsen and Palmer, 2014). In Argentine, cattle brucellosis prevalence of the $2.10 \%$ was found in 2004, although a program of control and eradication was implemented (Aznar et al., 2014).

Lectin binding relies on the affinity of these substances for specific terminal sugars and for $\alpha$ or $\beta$ anomeric linkages to the penultimate residues. The lectin histochemistry method facilitates the identification of complex structures to which the terminal sugar attaches and may reveal physiological or pathological changes in cells, intracellular interactions or extracellular transport pathways (Gemeneir et al., 2009). Lectin histochemistry has been used in the evaluation of glycoprotein expression in reproductive infections in several animal species, and changes in glycoproteins have been suggested in different studies where the patterns of lectin binding were modified (Pérez et al., 1998).

This fact has been reported in bovine sexuallytransmitted diseases as the uterine and tubarian epithelium of heifers infected with Tritrichomonas foetus and Campylobacter fetus venerealis (Cipolla et al., 1998; Cobo et al., 2004). These changes are related to the adhesion capacity and invasivity of the microorganisms. In relation with $B$. abortus, only two reports about the binding pattern of different bacterial strains have been published (Corbel et al., 1983a,b). More recently, the presence of beta 1,2 glucooligosaccharides in $B$. abortus was demonstrated as these sugars were recognized by c-lectins of the immune system cells and were involved in the pathogenesis of the disease (Poester et al., 2013; Zhang et al., 2016).

However, no information has been found about the carbohydrate pattern changes related to B. abortus infection in bovine fetuses and placentas.

The purpose of this study was to demonstrate the effects of presence of $B$. abortus on the lectin binding pattern on fetal lungs and placenta with the isolation of the bacterium.

\section{Sample selection}

Materials and Methods

Samples of bovine fetuses or stillborn lungs $(\mathrm{n}=6)$ and placenta $(\mathrm{n}=5)$, with $B$. abortus isolation, were selected from a previous study of experimentally inoculated heifers at 5 months of gestation with B. abortus 2308 (Fiorentino et al., 2008). Negative controls consisted of 3 fetuses and placenta with non-infectious abortion and with similar gestational age (> 7 months) than fetuses with $B$. abortus diagnosis. 


\section{Histology}

For histological examination, tissues obtained from the lungs and placenta were fixed in neutral-buffered $10 \%$ formalin, routinely embedded in paraffin wax, sectioned at $5 \mu \mathrm{m}$, and stained with hematoxylin and eosin (H\&E). Histopathological changes were identified and lesions were recorded and classified (Campero et al., 2003).

\section{Immunohistochemistry}

A commercial avidin-biotin complex kit (Vectastain ABC Elite, Rabbit IgG; Vector Laboratories, Burlingame, CA, USA) was used (Cobo et al., 2004; Campero et al., 2005). Briefly, paraffin-embedded tissue sections $(5 \mu \mathrm{m})$ were mounted on 3aminopropyltriethoxy-silane coated slides (P8920; Sigma Diagnostics, St Louis, MO, USA) and dewaxed with xylene. To quench endogenous peroxidase, the sections were incubated in $\mathrm{H}_{2} \mathrm{O}_{2} 3 \%$ in methanol for 10 min at room temperature, and then passed through a graded alcohol series before rinsing three times in deionized water and phosphate-buffered saline (PBS; $\mathrm{pH} 7.2,0.01 \mathrm{M})$. Afterwards, $0.1 \%$ protease enzyme (P1547; Sigma) in Tris-buffered saline (pH 7.5; Dako, Carpinteria, CA, USA) was added for antigen retrieval. The slides were then rinsed twice for 3-min in PBS and treated with blocking solution (ABC kit) for $30 \mathrm{~min}$ at room temperature to block non-specific sites. Primary B. abortus antibody (B. abortus antiserum, DIFCO LABS, Detroit, Michigan, USA), diluted 1/200 in PBS, was applied for $45 \mathrm{~min}$ at $37^{\circ} \mathrm{C}$. After three rinses in $\mathrm{PBS}$, sections were incubated for $30 \mathrm{~min}$ at $37^{\circ} \mathrm{C}$ with secondary biotinylated rabbit anti-bovine IgG (Vector). After three additional rinses in $\mathrm{PBS}$, peroxidaselabelled avidin was applied at $37^{\circ} \mathrm{C}$ for $30 \mathrm{~min}$. Sections were rinsed again in PBS, and the enzyme activity was detected by treatment for 10 min with 3\% 3-amino-9ethylcarbazole in N,N-dimethylformamide (AEC Substrate-Chromogen System; Dako). After counterstaining with Mayer's hematoxylin, the slides were dehydrated and mounted (Crystal Mount; Biomeda Corporation, Foster City, CA, USA) for examination. B. abortus-natural infected fetal lung tissue was used as a positive control and nonimmune normal rabbit serum was substituted for primary antibody as a negative control.

\section{Lectin Histochemistry}

Paraffin wax-embedded sections $(5 \mathrm{~mm})$ were used. After dewaxing, sections were treated with $0.3 \%$ hydrogen peroxide in methanol for $30 \mathrm{~min}$ at room temperature (to inhibit the endogenous peroxidase), rinsed several times in 0.01M PBS ( $\mathrm{pH} 7.2)$, and treated with $0.1 \%$ bovine serum albumin in PBS for $15 \mathrm{~min}$. The sections were then incubated for $1 \mathrm{~h}$ at room temperature with biotinylated lectins. Seven lectins (Lectin Kit BK 1000; Vector) with different specificity were used (Table 1).
Table 1. Lectins used in the histochemical studies and their major specificities.

\begin{tabular}{|c|c|c|}
\hline Lectin & Acronym & Carbohydrate specificity ${ }^{\mathrm{a}, \mathrm{b}}$ \\
\hline $\begin{array}{l}\text { Concanavalia } \\
\text { ensiformis }\end{array}$ & ConA & $\alpha$-D-Man; $\alpha$-D-Gluc \\
\hline Glycine max & SBA & $\alpha$-D-GalNAc; $\alpha$ and $\beta$-Gal \\
\hline Dolichos biflorus & DBA & $\alpha-\mathrm{D}-\mathrm{GalNAc}$ \\
\hline Ulex europaeus-I & UEA-1 & $\alpha-\mathrm{L}-\mathrm{Fuc}$ \\
\hline Triticum vulgaris & WGA & $\alpha-\mathrm{D}-\mathrm{GlcNac}>>\mathrm{NeuNac}$ \\
\hline$\frac{\text { Arachis }}{\text { hypogaea }}$ & PNA & $\beta-\mathrm{D}-\mathrm{Gal}(1-3) \mathrm{GalNA}$ \\
\hline $\begin{array}{l}\text { Ricinus } \\
\text { communis-I }\end{array}$ & RCA-1 & $\beta-\mathrm{D}-\mathrm{Gal}>\alpha-\mathrm{D}-\mathrm{Gal}$ \\
\hline
\end{tabular}

Optimal lectin concentration was $30 \mathrm{mg} / \mathrm{mL}$ in PBS for all lectins, except for PNA, which was applied at a concentration of $10 \mathrm{mg} / \mathrm{mL}$. The slides were incubated with an avidin-biotin-peroxidase complex (ABC) (Vector) for $45 \mathrm{~min}$. The horseradish peroxidase was activated by incubation for 1-2 min with a diaminobenzidine commercial kit (Dako). Specimens were rinsed in distilled water, dehydrated with graded ethanol solutions, cleared in xylene and mounted in Permount (Fisher Scientific International, Hampton, $\mathrm{NH}$, USA). Controls for lectin staining included: exposure to horseradish-peroxidase and substrate medium without lectin and blocking by incubation with the appropriate blocking sugars $(0.1$ to $0.2 \mathrm{M}$ in PBS) for $1 \mathrm{~h}$ at room temperature before applying to the sections. The intensity of lectin binding was subjectively scored from (-) (none) to +++ (strongly positive) following the system used previously (Fernández et al., 2014; Díaz et al., 2017). The structures studied in the lungs were glycocalix and cytoplasm of the epithelium of bronchi, bronchioli and alveoli and vascular endothelium. Endothelium, mesenchyme, mononuclear throphoblast and binucleate giant cells were observed in placentas.

\section{Results and Discussion}

Lectins are glycoproteins or proteins of non-immune origin that are obtained from plants and animals. They have been used in many areas of diagnostic research, mainly those related to changes in the expression of membrane and cytoplasmic glycoconjugates (Walker, 1989; Pilobello and Mahal, 2007). In the present work, the effect of B. abortus on lectin-histochemical patterns in infected lungs and placentas in comparison to uninfected controls was evaluated.

As expected, no histopathogical lesions were found in the non-infected fetuses and placentas. Table 2 shows the histophatological and immunohistochemical findings in fetuses/stillbirth lungs and placentas with $B$. abortus isolation. 
Table 2. Histophatological and immunohistochemical findings in fetuses/stillbirth lungs and placentas with Brucella abortus isolation.

\begin{tabular}{|c|c|c|c|c|c|c|}
\hline \multirow{2}{*}{ Sample $N^{\circ}$} & \multirow{2}{*}{$\begin{array}{l}\text { Fetuses/stillbirth } \\
\text { age }\end{array}$} & \multirow{2}{*}{ Culture } & \multicolumn{2}{|c|}{ Histopathological lesions $^{1}$} & \multicolumn{2}{|c|}{ Immunohistochemical $^{2}$} \\
\hline & & & Lungs & Placenta & Lungs & Placenta \\
\hline 99 & 1 day & + & +++ & $\mathrm{nc}$ & +++ & $\mathrm{nc}$ \\
\hline 100 & 3 days & + & +++ & + & + & +++ \\
\hline 161 & 8 months & + & +++ & nc & +++ & $\mathrm{nc}$ \\
\hline 160 & 8 months & + & +++ & nc & ++ & nc \\
\hline 135 & 8 months & + & +++ & nc & ++ & $\mathrm{nc}$ \\
\hline 141 & 8 months & + & $\mathrm{nc} *$ & + & $\mathrm{nc}^{*}$ & +++ \\
\hline 142 & 8 months & + & $\mathrm{nc}^{*}$ & ++ & $\mathrm{nc}^{*}$ & +++ \\
\hline 97 & 7 months & + & +++ & + & + & ++ \\
\hline 150 & 8 months & + & $\mathrm{nc}^{*}$ & ++ & $\mathrm{nc} *$ & +++ \\
\hline Controls & $>7$ months & $(-)$ & $(-)$ & $(-)$ & $(-)$ & $(-)$ \\
\hline
\end{tabular}

(1): Lesions: (-) no lesions observed; +: mild; ++: moderate; +++: severe. (2): Amount of antigen: (-): negative; +: low; ++: moderate; +++: abundant. nc: not collected sample. nc*: alive calf.

B. abortus-positive aborted fetuses developed histopathological changes similar to those described by other authors in experimental and natural infections (López et al., 1984; Sözmen et al., 2004). A multifocal distribution of severe bronchopneumonia was the most common change that was found in the lungs of the examined fetuses. The predominant inflammatory infiltrate was composed of macrophages, lymphocytes and neutrophils. This infiltrate was located in the interalveolar septa and was less abundant in lumina of alveoli and bronchi. In agreement with that previously reported, the fibrinous pleuritis was a lesion found only in some infected fetuses (Xavier et al., 2009). Placentitis was found in all the placentas examined, but the intensity of the lesion varied from slight to moderate. Mononuclear infiltration was found more frequently than polymorphonuclear infiltration as was previously reported in ovines by Yaziciouglu and Hazarogli (2000). Bacterial colonies were found in the necrotic areas of villi of one sample. Necrotic vasculitis with necrosis and mononuclear cell infiltration in the vessel walls was observed in two placentas. The necrotic placentitis affecting the depth of the villus was similar to that previously described in bovines and ovines (Yazicioglu and Haziroglu, 2000; Xavier et al., 2009). However, differently from that observed in previous reports, the polymorphonuclear neutrophils were found only in two placentas (Pérez et al., 1998). This observation is in agreement with the lung results, where only one fetus showed neutrophilic infiltrate, but not in agreement with the results of other works (Pérez et al., 1998). These differences could be originated by some differences in the experimental conditions, as Xavier et al. (2009) inoculated the animals at a later age while Perez et al. (1998) obtained the lungs only by natural infection abortion.
The results obtained by immunohistochemistry are similar in bovines, goats, ovines and mice infected with Brucella spp (Meador et al., 1986; Pérez et al., 1998; Yazicioglu and Haziroglu, 2000; Sözmen et al., 2004). Labelled B. abortus was seen in all evaluated tissues from infected fetuses and placentas but not in controls. It was demonstrated that $B$. abortus is able to replicate and persist within mouse and human lung epithelial cells (Kahl-McDonagh et al., 2007; Ferrero et al., 2009). However, in the present work, immunohistochemistry positivity to B. abortus was not found in epithelial lung cells. In the placentas, bacteria were detected extracellular in the necrotic areas and in the macrophages and mononuclear trophoblasts, but not in the cytoplasm of binucleated giant cells. In the lungs, immunolabeling was detected in macrophages and extracellular in the exudate found in the alveoli and bronchial lumen (Fig. 1). These localizations are in accordance with the characteristics of Brucella infections. The members of the Brucella genus are facultative intracellular pathogens that enter phagocytic cells such as neutrophils, macrophages and trophoblast cells and inhibit the killing mechanism of these professional phagocytic cells (Gorvel and Moreno, 2002). Furthermore, Brucella has the ability to interfere with intracellular trafficking, preventing fusion of the Brucella-containing vacuole with lysosome markers, and directing the vacuole towards a compartment that has rough endoplasmic reticulum, which is highly permissive to intracellular replication of Brucella (Pizarro-Cerdá et al., 2000). However, some nonphagocytic cells may also be invaded by $B$. abortus in cell lines in vitro (Pizarro-Cerdá et al., 1998).

Lectin binding patterns for the seven lectins in lungs and placentas of the infected and non-infected animals are summarized in Tables 3 and 4. 
Table 3. Lectin staining pattern in placentas of cows infected with Brucella abortus (Brc) and uninfected controls (C).

\begin{tabular}{|c|c|c|c|c|c|c|c|c|c|c|c|c|c|c|}
\hline \multirow{2}{*}{ Placenta } & \multicolumn{2}{|c|}{ UEA1 } & \multicolumn{2}{|c|}{ WGA } & \multicolumn{2}{|c|}{ RCA1 } & \multicolumn{2}{|c|}{ ConA } & \multicolumn{2}{|c|}{ PNA } & \multicolumn{2}{|c|}{ SBA } & \multicolumn{2}{|c|}{ DBA } \\
\hline & $\mathrm{C}$ & $\mathrm{Brc}$ & $\mathrm{C}$ & $\mathrm{Brc}$ & $\mathrm{C}$ & $\mathrm{Brc}$ & $\mathrm{C}$ & $\mathrm{Brc}$ & $\mathrm{C}$ & $\mathrm{Brc}$ & $\mathrm{C}$ & $\mathrm{Brc}$ & $\mathrm{C}$ & $\mathrm{Brc}$ \\
\hline \multicolumn{15}{|l|}{ Trofoblast } \\
\hline Glycocalix & $(-)$ & + & +++ & ++ & +++ & +++ & + & ++ & $(-)$ & ++ & +++ & +++ & $(-)$ & +++ \\
\hline Apical cytoplasm & $(-)$ & + & + & + & ++ & ++ & $(-)$ & + & $(-)$ & + & + & ++ & $(-)$ & ++ \\
\hline Endothelium & $(-)$ & $(-)$ & + & + & ++ & + & + & + & $(-)$ & $(-)$ & + & + & $(-)$ & $(-)$ \\
\hline Mesenchyme & $(-)$ & + & ++ & + & + & + & + & + & $(-)$ & $(-)$ & $(-)$ & + & $(-)$ & $(-)$ \\
\hline Binucleate giant cells & $(-)$ & $(-)$ & ++ & + & + & + & $(-)$ & + & $(-)$ & + & $(-)$ & $(-)$ & $(-)$ & $(-)$ \\
\hline
\end{tabular}

Table 4. Lectin staining pattern in fetal bovine lungs infected with Brucella abortus (Brc) and uninfected controls (C).

\begin{tabular}{|c|c|c|c|c|c|c|c|c|c|c|c|c|c|c|}
\hline \multirow{2}{*}{ Lung } & \multicolumn{2}{|c|}{ UEA1 } & \multicolumn{2}{|c|}{ WGA } & \multicolumn{2}{|c|}{ RCA1 } & \multicolumn{2}{|c|}{ ConA } & \multicolumn{2}{|c|}{ PNA } & \multicolumn{2}{|c|}{ SBA } & \multicolumn{2}{|c|}{ DBA } \\
\hline & $\mathrm{C}$ & $\mathrm{Brc}$ & $\mathrm{C}$ & $\mathrm{Brc}$ & $\mathrm{C}$ & $\mathrm{Brc}$ & $\mathrm{C}$ & $\mathrm{Brc}$ & $\mathrm{C}$ & $\mathrm{Brc}$ & $\mathrm{C}$ & $\mathrm{Brc}$ & $\mathrm{C}$ & $\mathrm{Brc}$ \\
\hline \multicolumn{15}{|l|}{ Bronchi } \\
\hline Glycocalix & $(-)$ & ++ & ++ & ++ & + & +++ & ++ & +++ & $(-)$ & ++ & ++ & +++ & $(-)$ & +++ \\
\hline Apical cytoplasm & $(-)$ & ++ & + & + & $(-)$ & ++ & + & ++ & $(-)$ & + & + & ++ & $(-)$ & ++ \\
\hline \multicolumn{15}{|l|}{ Bronchiole } \\
\hline Glycocalix & $(-)$ & ++ & ++ & +++ & + & +++ & ++ & +++ & $(-)$ & ++ & ++ & +++ & $(-)$ & + \\
\hline Apical cytoplasm & $(-)$ & + & + & ++ & $(-)$ & ++ & + & ++ & $(-)$ & ++ & + & ++ & $(-)$ & $(-)$ \\
\hline \multicolumn{15}{|l|}{ Alveoli } \\
\hline Glycocalix & $(-)$ & + & +++ & ++ & ++ & +++ & + & ++ & $(-)$ & ++ & ++ & +++ & $(-)$ & + \\
\hline Apical cytoplasm & $(-)$ & $(-)$ & + & ++ & $(-)$ & ++ & $(-)$ & ++ & $(-)$ & + & + & ++ & $(-)$ & $(-)$ \\
\hline Endothelium & $(-)$ & $(-)$ & $(-)$ & ++ & ++ & ++ & $(-)$ & ++ & $(-)$ & $(-)$ & ++ & + & $(-)$ & + \\
\hline
\end{tabular}

An increase in the binding to the majority of the lectins was observed in the lungs. The changes were most evident for UEA-1, RCA-1, PNA and DBA (Fig. 2), thus demonstrating an increase in the fucose, galactose and $\mathrm{N}$-acetyl-galactosamine residues (Golstein and Hayes, 1978). DBA binding was found as a finely granulary intracytoplasmic staining in some macrophages.

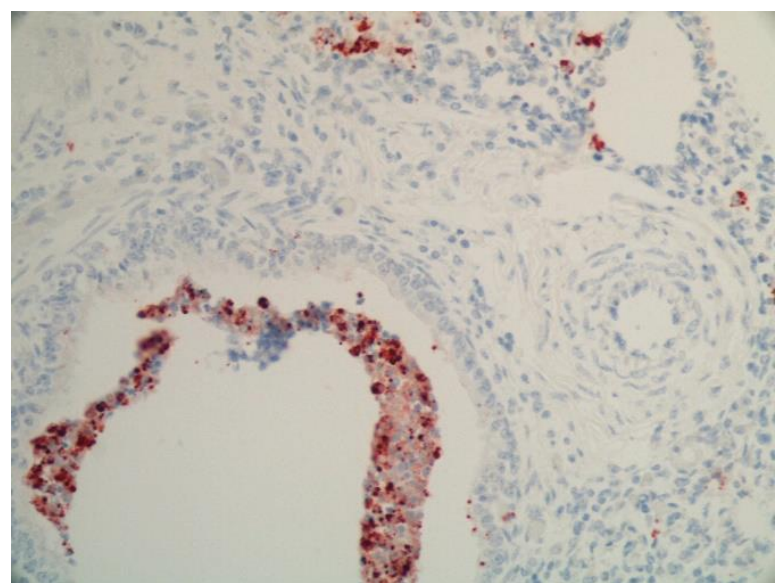

Fig. 1. Brucella abortus in the bronchial lumen of a bovine fetus with bronchopneumonia. IHQ 40x.

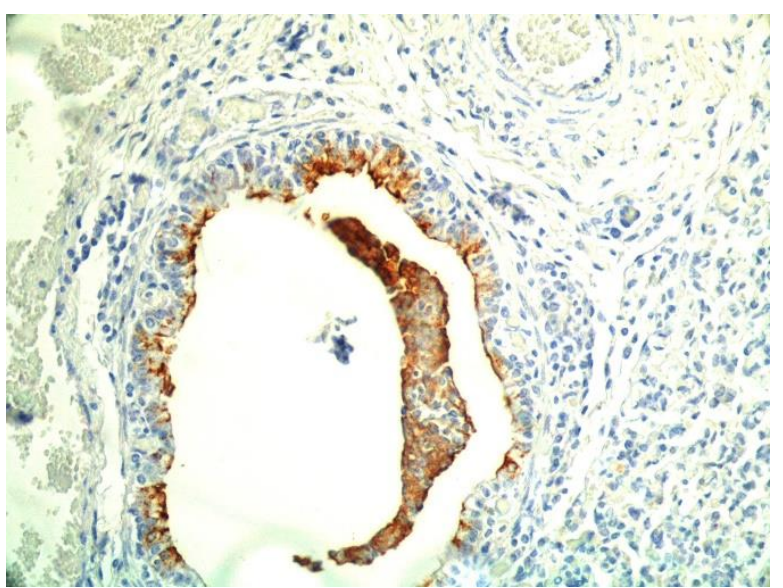

Fig 2. Pattern of DBA found in bovine fetal lung with isolation of B. abortus. 40x.

We have not found previous reports on lectin histochemistry in fetal bovine lungs infected with $B$. abortus. In normal human fetus lungs, Barkhordari et al. (2004) found a similar lectin binding pattern in the endothelium but not in bronchial or alveolar cells, thus demonstrating the variability between the species for the epithelium patterns of glycoconjugates. On the 
other hand, the changes observed in fetuses infected with Campylobacter fetus were less marked than those found in the present study (Morrell et al., 2010). Therefore, the comparison of these lectinohistochemical results demonstrates that the glyconconjugate modifications in the lung epithelium are specific for each infecting microorganism. In our study, the lecting binding pattern in mononuclear normal trophoblasts was similar to that reported by Munson et al. (1989), shows the scarce binding by DBA and UEA-1 lectin in the villus.

In the binucleate giant cells, the binding to some lectins, such as UEA-1 and WGA, was similar to that found in previous reports in bovine near-term placenta (Jones et al., 1994). However, the affinity for DBA and SBA in the near-term placenta binucleate giant cells was higher than the one found in the present study (Jones et al., 1994).

This difference could be attributed to changes in the secretion activity of these cells during pregnancy (Woodwing and Burton, 2008). In the mononuclear trophoblast of the placentas of infected animals, an increase in the binding to PNA, DBA and UEA-1 was found. However, in the other analyzed structures like blood vessels, mesenchyme and binucleate giant cells, the changes were less relevant. This result is in agreement with the presence of $B$. abortus in the cytoplasm of these cells evidenced by immunolabeling. The changes in the lecting binding pattern could be a response to the penetration of the bacterium in the mononuclear trophoblast.

In a recent work, Carvalho Neta et al. (2008) reported changes in the expression of 62 genes ( 25 increased and 37 downregulated expression) in explants of chorioallantoic bovine membrane infected with $B$. abortus. The lectin pattern is an indirect result of the gene expression (Gimeno and Barbeito, 2004). In the present work, an increase in the binding of UEA-1, DBA and PNA in the trophoblasts of infected animals was found.

These changes in the labeling pattern evidenced a modification in the expression of lectins in cells infected with Brucella. In uninfected binucleated giant cells, there were no significant changes in the lectin pattern.

Notably, phagocytic cells as trophoblasts mononuclear and macrophages showed an intracellular labeling to DBA, similar to that observed in immunohistochemistry. As mentioned above, there are no previous reports on the affinity of lectins on animal tissues infected with B. abortus. However, in a study on Brucella cultures, the microorganism showed affinity for the Con-A lectin, demonstrating the presence of glucose and mannose residues, although they were negative for lectins that bind to $\mathrm{N}$-acetylgalactosamine (Corbel et al., 1983a,b).
In our study, Brucella labeling for the Con-A lectin was not observed but labeling was observed for DBA lectin in phagocytic cells. These differences could be due to changes in the bacterial surface generated by eukaryotic cell endocytic systems.

\section{Conclusion}

The present lectin histochemical study, supported by bacteriological cultures, immunohistochemistry and histopathology, revealed a distinctive pattern of oligosaccharide distribution in the lungs and placenta from B. abortus-infected fetuses and the positive DBA binding of this bacterium.

\section{Acknowledgments}

We thank to A. Mendez for media preparation, R.C. Malena and M.A. Poso for their efficient assistance. We acknowledge Yosef Huberman for language revision.

\section{Conflict of interest}

The authors declare that there is no conflict of interests.

\section{References}

Aznar, M.N., Samartino, L.E., Humblet, M.F. and Saegerman, C. 2014. Bovine brucellosis in Argentina and bordering countries: update. Transbound Emerg. Dis. 61(2), 121-133.

Barkhordari, A., Stoddart, R., Mc Clure, S. and McClure, J. 2004. Lectin histochemistry of normal human lung. J. Mol. Histol. 35, 147-156.

Campero, C.M, Anderson, M.L., Walker, R.L., Blanchard, P.C., Barbano, L., Chiu, P., Martínez, A., Combessies, G., Bardon, J.C. and Cordeviola, J.. 2005. Identification of Campylobacter fetus in natural cases of bovine and ovine abortions. J. Vet. Med. Series B. 52, 138-141.

Campero, C.M., Moore, D.P., Odeon, A.C., Cipolla, A.L. and Odriozola, E. 2003. Aetiology of bovine abortion in Argentina. Vet. Res. Com. 27, 359-369.

Carvalho Neta, A.V., Stynen, A.P., Paixao, T.A., Miranda, K.L., Silva, F.L., Roux, C.M., Tsolis, R.M., Everts, R.E., Lewin, H.A., Adams, L.G., Carvalho, A.F., Lage, A.P. and Santos R.L. 2008. Modulation of the bovine trophoblastic innate immune response by Brucella abortus. Infect. Immun. 76, 1897-1907.

Cipolla, A., Paolicchi, F., Poso, M., Morsella, C.G., Casaro, A.P., Massone, A.R., Villegas, R., Callejas, S. and Gimeno, E.J. 1998. Lectin-binding sites in uterus and oviduct of normal and Campylobacter fetus subspecies venerealis-infected heifers. Eur. J. Histochem. 42, 63-70.

Cobo, E.R., Campero, C.M., Gimeno, E.J. and Barbeito, C.G. 2004. Lectin binding pattern and immunohistochemical antigen detection in genitalia of Tritrichomonas foetus-infected heifers. J. Comp. Pathol. 131, 127-134.

Corbel, M.J., Cockrem, D.S. and Brewer, R.A. 1983a. The interaction of Brucella cell surface components 
with plants agglutinins. Develop. Biol. Standard. 56, 169-175.

Corbel, M.J., Cockrem, D.S. and Brewer, R.A. 1983b. Differentiation of smooth and rough Brucella strains by lectins. Vet. Rec. 113, 261-262.

Díaz, M.C., González, N.V., Zanuzzi, C.N., Najle, R. and Barbeito, C.G. 2017. Lectin histochemistry for detecting cadmium-induced changes in the glycosylation pattern of rat placenta. Biotech. Histochem. 92(1), 36-45.

Fernández, P.E., Diessler, M.E., Pachame, A., Ortega, H.H., Gimeno, E.J., Portiansky, E.L. and Barbeito, C.G. 2014. Intermediate filament proteins expression and carbohydrate moieties in trophoblast and decidual cells of mature cat placenta. Reprod. Domest. Anim. 49(2), 263-269.

Ferrero, M., Fossati, C. and Baldi, C. 2009. Smooth Brucella strains invade and replicate in human lung epithelial cells without inducing cell death. Microb. Infect. 11, 276-283.

Fiorentino, M.A., Campos, E., Cravero, S., Arese, A., Paolicchi, F.A., Campero, C.M. and Rossetti, O. 2008. Protection levels in vaccinated heifers with experimental vaccines Brucella abortus M1-luc and INTA 2. Vet. Microbiol. 132, 302-311.

Gemeneir, P., Misloviĉová, D., Tkáĉ, J., Ŝvitel, J., Pätoprstý, V., Hrabárová, E., Kogan, G. and Kožár, T. 2009. Lectinomics II: A highway to biomedical/clinical diagnotics. J. Biotech. Adv. 27, $1-15$.

Gimeno, E. and Barbeito, C. 2004. Glicobiología, una nueva dimensión para el estudio de la biología y de la patología. Anales de la Academia Nacional de Agronomía y Veterinaria. 58, 6-34.

Golstein, I. and Hayes, C. 1978. The lectins: carbohydrate binding protein of plants and animals. Adv. Carbohydr. Chem. Biochem. 35, 127-340.

Gorvel, J.P. and Moreno, E. 2002. Brucella intracellular life: from invasion to intracellular replication. Vet. Microbiol. 90, 281-297.

Jones, C.J.P., Koob, B., Stoddart, R.W., Hoffmann, B. and Leiser, R. 1994. Lectin-histochemical analysis of glycans in ovine and bovine near-term placental binucleate cells. Cell Tissue Res. 278, 601-610.

Kahl-McDonagh, M., Arenas-Gamboa, A. and Ficht, T. 2007. Aerosol infection of BALB/c mice with Brucella melitensis and Brucella abortus and protective efficacy against aerosol challenge. Infect. Immun. 75, 4923 -4932.

López, A., Hitos, F., Pérez, A. and Navarro Fierro, R.R. 1984. Lung lesions in bovine fetus aborted by Brucella abortus. Can. J. Comp. Med. 48, 275-277.

Meador, V., Tabatabai, L., Hagemoser, W. and Deyoe, B.L. 1986. Identification of Brucella abortus in formalin-fixed, paraffin-embedded tissues of cows, goats, and mice with an avidin-biotin-peroxidase complex immunoenzymatic staining technique. Am. J. Vet. Res. 47, 2147-2150.

Morrell, E., Barbeito, C., Odeón, C., Gimeno, E. and Campero, C. 2010. Histopathological, immunohistochemical, lectinhistochemical and molecular findings in spontaneous bovine abortions by Campylobacter fetus. Rep. Dom. Anim. 46, 309315.

Munson, L., Kao, J.J. and Schlafer, D.H. 1989. Characterization of glycoconjugates in the bovine endometrium and chorion by lectin histochemistry. J. Reprod. Fertil. 87, 509-517.

Olsen, S.C. and Palmer, M.V. 2014. Advancement of knowledge of Brucella over the past 50 years. Vet. Pathol. 51(6), 1076-1089.

Pérez, J., Quezada, M., López, J., Casquet, O., Sierra, M.A. and Martín de las Mulas, J. 1998. Inmunohistochemical detection of Burcella abortus antigens in tissues from aborted bovine fetuses using a commercially available polyclonal antibody. J. Vet. Diagn. Invest. 10, 17-21.

Pilobello, K. and Mahal, L.K. 2007. Lectin microarrays for glycoprotein analysis. Methods Mol. Biol. 385, 193-203.

Pizarro-Cerdá, J., Méresse, S., Parton, R.G., van der Goot, G., Sola-Landa, A., Lopez-Goñi, I., Moreno, E. and Gorvel, J.P. 1998. Brucella abortus transits through the autophagic pathway and replicates in the endoplasmic reticulum of nonprofessional phagocytes. Infect. Immun. 66, 5711-5724.

Pizarro-Cerdá, J., Moreno, E. and Gorvel, J.P. 2000. Invasion and intracellular trafficking of Brucella abortus in nonphagocytic cells. Microb. Infect. 2(7), 829-835.

Sözmen, M., Erginsoy, S., Genc, O., Beytut, E. and Özcan, K. 2004. Inmunohistochemical and microbiological detection of Brucella abortus in aborted bovine fetuses. Acta Vet. Brno 73, 465-472.

Poester, F.P., Samartino, L.E. and Santos, R.L. 2013. Pathogenesis and pathobiology of brucellosis in livestock. Rev. Sci. Tech. 32(1), 105-115.

Walker, R.A. 1989. The use of lectins in histopathology. Pathol. Res. Pract. 185, 826-835.

Woodwing, P. and Burton, G. 2008. Comparative Placentation. Structures Function and Evolution. Ed. Springer-Verlag. Berlin.

Xavier, M.N., Paixa, T.A., Poester, F.P., Lage, A.P. and Santos, R.L. 2009. Pathological, immunohistochemical and bacteriological study of tissues and milk of cows and fetuses experimentally infected with Brucella abortus. J. Comp. Path. 140(2-3), 149-157.

Yazicioglu, O. and Haziroglu, R. 2000. Pathological and immunoperoxidase studies of the placental lesions of ovine brucellosis. Israel J. Vet. Med. 55, 103-107. 
Zhang, H., Palma, A.S., Zhang, Y., Childs, R.A., Liu, Y., Mitchell, D.A., Guidolin, L.S., Weigel, W., Mulloy, B., Ciocchini, A.E., Feizi, T. and Chai, W. 2016. Generation and characterization of $\beta 1,2-$ gluco-oligosaccharide probes from Brucella abortus cyclic $\beta$-glucan and their recognition by $\mathrm{C}$-type lectins of the immune system. Glycobiology 26(10), 1086-1096. 